\title{
The nature of impairments of memory in patients with end-stage renal disease (ESRD)
}

Article

Accepted Version

Jones, D. J.W., Harris, J. P., Vaux, E., Hadid, R., Kean, R. and Butler, L. T. (2015) The nature of impairments of memory in patients with end-stage renal disease (ESRD). Physiology \& Behavior, 147. pp. 324-333. ISSN 0031-9384 doi: https://doi.org/10.1016/j.physbeh.2015.05.008 Available at https://centaur.reading.ac.uk/40310/

It is advisable to refer to the publisher's version if you intend to cite from the work. See Guidance on citing.

Published version at: http://www.sciencedirect.com/science/article/pii/S0031938415002681

To link to this article DOI: http://dx.doi.org/10.1016/j.physbeh.2015.05.008

Publisher: Elsevier

All outputs in CentAUR are protected by Intellectual Property Rights law, including copyright law. Copyright and IPR is retained by the creators or other copyright holders. Terms and conditions for use of this material are defined in the End User Agreement.

www.reading.ac.uk/centaur 
Central Archive at the University of Reading

Reading's research outputs online 
"The nature of impairments of memory in patients with end-stage renal disease (ESRD)."

Daniel J. W. Jones ${ }^{\mathrm{a}}$, , John P. Harris ${ }^{\mathrm{a}}$, Emma Vaux ${ }^{\mathrm{b}}$, Rebecca Hadid ${ }^{\mathrm{a}}$, Rebecca Kean ${ }^{\mathrm{a}}$, Laurie T. Butler ${ }^{\mathrm{a}}$

${ }^{a}$ School of Psychology and Clinical Language Sciences, University of Reading, Earley Gate, Whiteknights, Reading, Berkshire, RG6 6AL, U.K.

b Department of Renal Medicine, Royal Berkshire NHS Foundation Trust, London Road, Reading, RG1 5AN, U.K.

\section{Corresponding author:}

Daniel J. W. Jones

School of Psychology and Clinical Language Sciences

University of Reading

Earley Gate, Whiteknights

Reading, Berkshire

RG6 6AL

United Kingdom

Tel: +447506724244

Email: d.jones6@ reading.ac.uk 


\begin{abstract}
Possible impairments of memory in end-stage renal disease (ESRD) were investigated in two experiments. In Experiment 1, in which stimulus words were presented visually, participants were tested on conceptual or perceptual memory tasks, with retrieval being either explicit or implicit. Compared with healthy controls, ESRD patients were impaired when memory required conceptual but not when it required perceptual processing, regardless of whether retrieval was explicit or implicit. An impairment of conceptual implicit memory (priming) in the ESRD group represented a previously unreported deficit compared to healthy aging. There were no significant differences between pre- and immediate post-dialysis memory performance in ESRD patients on any of the tasks. In Experiment 2, in which presentation was auditory, patients again performed worse than controls on an explicit conceptual memory task. We conclude that the type of processing required by the task (conceptual vs. perceptual) is more important than the type of retrieval (explicit vs. implicit) in memory failures in ESRD patients, perhaps because temporal brain regions are more susceptible to the effects of the illness than are posterior regions.
\end{abstract}

Keywords:

Memory; End-stage renal disease (ESRD); Implicit; Explicit; Conceptual; Perceptual. 


\subsection{Introduction}

In end-stage renal disease (ESRD), failure of both kidneys leads to a build-up of waste materials (e.g. urea, toxins and mineral salts) accumulating in the blood, so that a form of renal replacement therapy (haemodialysis, peritoneal dialysis, or transplant) is required in order for a patient to survive. ESRD is associated with various cognitive impairments (Hart \& Kreutzer, 1988), for example, visual attention (Etgen et al., 2009), executive functioning (Jassal et al., 2006), and psychomotor speed (Griva et al., 2003). In addition, various aspects of memory have been shown to be impaired: verbal and visual memory (Elias et al., 2009; Kurella et al., 2004), working memory (Buchman et al., 2009) and episodic (explicit) memory (Thornton et al., 2007). The aim of the present study was to explore memory impairments in ESRD in greater depth.

In investigations of normal human memory, two key distinctions have been made, one of which is between explicit and implicit memory (see Butler \& Berry (2001) for review). Explicit memory involves conscious memories of facts or information that can be articulated or communicated (e.g. remembering the time of an appointment). In contrast, implicit memories are not available to conscious recollection and consequently cannot be articulated, but rather are demonstrated in priming or procedural memory (e.g. remembering how to ride a bicycle or grammar structure). Importantly, different brain areas underlie the two types of memory system; dissociations have been displayed in amnesic patients with hippocampal damage, episodic explicit memory is impaired whereas implicit memory is spared (Aggleton \& Brown, 1999; Gabrieli, Fleischman, Keane, Reminger \& Morrell, 1995). The second distinction is between conceptual and perceptual memory. Conceptually driven tasks require semantic processing of the retrieval cue, (e.g. understanding the meaning of a word) whereas perceptually driven tasks involve processing of its perceptual features (e.g. counting the number of letters in a word) (Roediger, 1990). The temporal lobes have been shown to have a prominent role in conceptual processing (Martin, 2007; Pobric, Jefferies \& Lambon Ralph, 2007; Visser, Jefferies \& Lambon Ralph, 2010) whereas perceptual processing is thought to involve more posterior regions (Blaxton et al. 1996; Schacter., 1992).

These different types of memory have been examined in Alzheimer's disease (AD), normal aging and amnesic patients but not yet in ESRD (Becaria, Campbell \& Bondy, 2002). Our expectation was that the pattern of impairment on different tests of memory could provide 
information about the vulnerability of different brain regions to the effects of the illness, and the relationship with healthy aging.

Furthermore, cognitive performance in ESRD patients receiving haemodialysis appears to fluctuate with the time at which they are tested during their weekly dialysis cycle, however, there is disagreement about the relationship. For example, Griva et al. (2003), tested patients immediately before and again 24 hours after dialysis, finding significant improvements in attention, concentration, verbal and visual memory and psychomotor speed, post-dialysis. In contrast, Murray et al., (2007) examined global cognitive functioning at four different times relative to dialysis: one hour before, one hour into a session, one hour after, and the following day. Cognitive performance was at its lowest during the dialysis session, and improved one hour after dialysis. Performance was best one hour before the session and on the following day, with no significant differences between the results at these two times, a finding different from that of Griva et al. Thus the potential costs and benefits of dialysis on cognitive function, and how these might vary over time, are not clear at present. In Experiment 1 of the present study, we tested memory immediately before and directly after (ten minutes) dialysis to determine whether dialysis can have an immediate effect on cognitive performance.

In Experiment 1, our participants with ESRD were randomly assigned to either an implicit or an explicit memory testing group. In both groups, participants completed a perceptual and a conceptual memory task, involving a learning (encoding) and a recall phase (retrieval), separated by a distractor task. The tasks were the same in both groups, with only the different instructions establishing whether recall was to be implicit or explicit. To measure the potential effects of dialysis on memory, patients were tested once immediately preceding haemodialysis, and once ten minutes after a different haemodialysis session, with testing sessions separated by one week to minimise patient fatigue. A healthy control group also completed the same tasks. In Experiment 1, stimulus presentation was always visual. In Experiment 2, to check whether effects were independent of presentation modality, we ran with auditory presentation a sub-set of the conditions in which significant differences were found in Experiment 1, again comparing patients and controls. In order to exclude participants who were clinically depressed or had severe cognitive impairment, we also ran some standard tests of mood and cognition on all participants. 
In summary, the aim of the study was to investigate the nature of the impairment of memory in ESRD, specifically the extent to which it depends on retrieval volition (implicit vs. explicit) and type of processing (perceptual vs. conceptual), and the immediate effects on these processes of haemodialysis.

\section{Experiment 1: Memory processing in ESRD with visual presentation}

\subsection{Method}

\subsubsection{Design}

The study was designed to determine the nature of memory impairment in patients undergoing haemodialysis. The study was conducted in accordance with the ethical principles of the Declaration of Helsinki, the Good Clinical Practice guidelines of the International Conference on Harmonisation, and local regulatory requirements. Ethical approval for the study was given by the National Research Ethics Service, UK, and the University of Reading Research Ethics Committee.

Patients were randomly assigned to either an explicit $(\mathrm{N}=14)$ or an implicit $(\mathrm{N}=16)$ group, completing both conceptual (e.g., Isingrini, Vazou and Leroy, 1996) and perceptual (e.g., Clarke and Butler, 2008) versions of each task. Each patient was tested once immediately preceding dialysis and once approximately 10 minutes after another haemodialysis session. These test sessions were separated by one week to reduce the effects of fatigue, with order counterbalanced over patients. Testing was standardised across sessions to ensure that patients were tested at a similar time-point the following week, i.e. if, say, a patient's first test was before the 6 am dialysis session a Monday, the second test session was conducted after the 6 am dialysis on the following Monday.

Healthy control participants were randomly assigned to either an explicit $(\mathrm{N}=16)$ or an implicit (N=20) group. Each participant completed the test procedure once. This single test session was compared to the pre-dialysis assessment conducted with the patient group. 


\subsubsection{Participants}

Thirty-six ESRD patients (mean age: 61.4 years, S.D: 16.6) were recruited from the Renal Unit, Royal Berkshire Hospital, Reading UK; 22 were male. Each patient was receiving haemodialysis three times per week for 3-5 hours per treatment; undergoing haemodialysis for a minimum of 90 days prior to testing (all had a Kt/v > 1.4). Exclusion criteria included a history of ophthalmological or neurological illness, and English was required as a first language. Consent was obtained by a consultant nephrologist independent of the study, and patients were tested in a quiet office on the renal ward. Comorbid conditions and other relevant history were taken from medical records.

Thirty-six healthy control participants (mean age: 59.3 years, S.D: 15.3) were recruited from a research volunteer panel maintained by the Department of Psychology at the University of Reading; 12 were male. Eligibility requirements were the same for the control group as for the ESRD patients, with an additional requirement of no history of renal disease. Control participants were given $£ 5$ to cover their expenses. They were tested in a quiet room within the Department of Psychology.

\subsubsection{Stimuli and Procedure}

\subsubsection{Apparatus}

Stimuli were presented on a Toshiba 17.3" LCD screen laptop computer using custom software written in Visual Basic 6.0 to display the stimuli. The participant was seated in a comfortable chair positioned approximately $80 \mathrm{~cm}$ from the screen. All participants completed a number of standard tests of cognition, ability to function in everyday life, and mood, namely the MMSE, IADL, NART and GDS (details below).

\subsubsection{Conceptual memory tasks}

Participants initially viewed a series of 36 words, each presented individually on screen. They were instructed to count the number of vowels $(\mathrm{a}, \mathrm{e}, \mathrm{i}, \mathrm{o}, \mathrm{u})$ in each word and to respond with the corresponding key (1-5). The task was self-paced, so that the next trial was initiated by the key-press to the previous trial. Four different lists were available so that different words could be used in different testing sessions. The lists are presented in Appendix 1, and some characteristics of the words in each list (length, frequency, familiarity, concreteness) are shown in Table 1. The list version and number were counterbalanced over participants, so 
that half the participants were tested using the two versions of List 1 and half using the two versions of List 2. Within each of these groups, half the participants were tested in their first test session on the Version 1 list and in their second on the Version 2 list, and the other half vice versa. Number of correct responses and response time were recorded.

Participants then viewed a series of category labels presented individually (for approximately 15 seconds) on the screen: e.g. carpenter's tools. The labels associated with each list are given in Appendix 2. The explicit group were instructed to think back to the list of words in which they had to count vowels. They were presented with six different categories in turn, and asked to say aloud any words seen previously during the counting task which fitted the currently presented category, e.g. hammer. The implicit group were presented with twelve different categories in turn (more categories were used in the implicit task as some were used as distractors). This group were instructed to merely say aloud as many examples of each category that came to mind, up to a maximum of eight, without reference to the counting task. All utterances were recorded by the experimenter. Half the category labels were drawn from a list of words seen in the previous counting task, and half from a second list which was not presented during counting. Different lists were available so that different words could be used in the two test sessions. The aim of presenting category labels from a list which had not been seen was to obtain a baseline measure of the number of exemplars which would be generated in the absence of any experience of those categories during the vowel counting task. 
Table 1. Characteristics of the word lists used in Experiment 1.

\begin{tabular}{lllll}
\hline List & Length (letters) & $\begin{array}{l}\text { Kucera/Francis } \\
\text { frequency }\end{array}$ & Familiarity & Concreteness \\
\hline V1L1 & $5.44(0.23)$ & $19.88(3.83)$ & $529.31(14.46)$ & $545.42(20.58)$ \\
V1L2 & $5.19(0.22)$ & $20.16(3.81)$ & $525.18(13.72)$ & $540.89(20.33)$ \\
V2L1 & $5.56(0.20)$ & $21.97(4.26)$ & $518.08(10.23)$ & $520.13(23.18)$ \\
V2L2 & $5.72(0.19)$ & $23.90(4.29)$ & $494.63(11.53)$ & $509.12(23.14)$ \\
F ratio & F 3,124 $=1.14$ & F 3,123 $=0.15$ & F 3,101 $=1.52$ & F 3,97 = 0.62 \\
$\boldsymbol{p}$ & 0.34 & 0.93 & 0.22 & 0.60 \\
\hline Values are means (with standard errors in brackets). Kucera/Francis frequency is occurrence per million words. Familiarity and concreteness
\end{tabular}

can both range from 100 to 700. Differences between word lists in these measures were non-significant by ANOVA (degrees of freedom differ between measures because, for some words, not all measures are given in the MRC Psycholinguistic database - Coltheart, 1981)

\subsubsection{Perceptual memory tasks}

Participants viewed a series of 32 words presented individually on the screen, drawn from one of the lists in Appendix 1. They were instructed to say each word aloud clearly and accurately, and then to move onto the next word by pressing the space bar. As in the conceptual task, allocation of lists to test sessions was counterbalanced across participants.

At retrieval, participants viewed a series of 32 word stems (the first three letters of a word, e.g. ele...) individually on the screen. The task was to complete verbally each of the word stems (e.g. "elephant") with the constraints that the word be English and not a proper noun (person, place or brand name). The next word stem appeared when the space bar was pressed. The explicit group were told to recall the encoding task, completing the stem only with a word they remembered reading aloud. They were instructed not to guess, and could "pass" a stem which they could not recall. The implicit group were told to complete the stems with the first word that came to mind. All responses were recorded by the experimenter. Half the word stems were drawn from the list of words seen in the previous reading aloud task, and half from a second list which was not presented during encoding, again to provide a baseline of completions not due to the experimental manipulation. 


\subsubsection{End questionnaire}

Participants in the implicit group completed a questionnaire at the end of testing, whose aim was to check whether they were using conscious (i.e. explicit) retrieval strategies. It asked whether or not the participant had noticed anything unusual about tests, or a link between the encoding and test phases of the stem completion task (i.e. "What did you think was the purpose of the stem completion task you just finished?"), or the category exemplar task (i.e. "Did you notice any relation between any of the words you saw earlier and any of the examples you produced on the category exemplar task?").

\subsubsection{Mini Mental State Exam (MMSE)}

The MMSE (Folstein, Folstein \& McHugh, 1975) is a short questionnaire designed to screen for cognitive impairment. The 30 questions assess memory, orientation to time, orientation to place, attention and language. A score of 25-30 indicates normal cognition, 21-24 mild, 10-20 moderate and $<9$ severe impairment.

\subsubsection{National Adult Reading Test (NART)}

The NART (Nelson \& Willeson, 1991) assesses pre-morbid intelligence in English-speaking individuals. Fifty words, whose reading difficulty varies, are shown on a single sheet, and have to be read aloud. Overall, verbal, and performance IQ can be estimated from the number of words correctly pronounced.

\subsubsection{Instrumental Activities of Daily Living scale (IADL)}

The IADL (Lawton \& Brody, 1969) assesses an individual's independence and how they deal with the demands of everyday life. Eight different domains are assessed, including food preparation, driving, and shopping; the scale ranges from 0 (low independence) to 8 (full independence).

\subsubsection{Geriatric Depression Scale (GDS)}

The GDS (Yesevage et al. 1983) is a 15-item screening tool for depression in the elderly. It is short and easy to administer using a number of questions about mood and anxiety to estimate a score of depression. A score of 0-4 is considered normal, 5-9 is mild depression and 10-15 is more severe depression. 
The order of pre and post-dialysis testing sessions was counterbalanced. Within the testing session, the memory-related tests were administered in the following order:

1. Vowel Counting Task (Conceptual)

2. Filler task: Arithmetic

3. Category Exemplar Task (Conceptual)

4. Filler task: MMSE

5. Word Stem Encoding Task (Perceptual)

6. Filler task: NART and GDS

7. Word Stem Completion Task (Perceptual)

8. IADL

9. End questionnaire

Between encoding and retrieval participants were given distractor/filler tasks which differed slightly between pre and post testing sessions. Both sessions contained a simple arithmetic task (adding and subtracting three to a series of numbers) between encoding and retrieval of the conceptual task. Between perceptual encoding and retrieval a Stroop task (conducted on the Toshiba laptop) was conducted in the pre-dialysis session and the NART and GDS were completed in the post-dialysis session. Testing sessions lasted approximately 45-60 minutes. After testing was complete, patients were fully debriefed.

\subsection{Results}

\subsubsection{Demographics}

Table 2 shows participant age, ratio of male to female, NART overall IQ, GDS score, MMSE and IADL score. Table 3 provides further information on patients' initial diagnoses, the duration of their haemodialysis and comorbidities. The control group $(M=59.9, S D=15.3)$ did not significantly differ in age from the patient group $(M=62.3, S D=16.4), t(64)=-$ $0.611, p=.54$. However, there were significant differences between the groups in MMSE scores, $t(64)=3.47, p=.001$, GDS scores, $t(64)=-3.58, p=.001$, and NART scores $t(64)=$ $4.38, p<.001$. Although significantly different between groups, NART and MMSE scores were both within normal range. Note that data from the 6 patients who were excluded 
because of their GDS score ( $>6$, suggesting a sign of depression) are not included in this table or the other analyses.

Table 2. Demographic data of participants in Experiment $1^{\mathrm{a}}$

\begin{tabular}{|c|c|c|c|c|}
\hline & \multicolumn{4}{|c|}{ Group } \\
\hline & \multicolumn{2}{|c|}{ Control $(\mathrm{N}=36)$} & \multicolumn{2}{|c|}{ Patient $(\mathbf{N}=30)^{*}$} \\
\hline & Mean & SD & Mean & SD \\
\hline Age & 59.9 & 15.3 & 62.3 & 16.4 \\
\hline NART Overall IQ & 121.8 & 4.1 & 114.8 & 8.5 \\
\hline GDS & 1.6 & 1.6 & 2.9 & 1.4 \\
\hline MMSE & 28.7 & 0.9 & 27.3 & 2.3 \\
\hline IADL & 8.0 & 0.0 & 7.9 & 0.6 \\
\hline $\mathbf{M} / \mathbf{F}$ & $12 / 24$ & - & $22 / 8$ & - \\
\hline
\end{tabular}


Table 3. Patient Characteristics in Experiment $1^{\mathrm{b}}$

\begin{tabular}{|c|c|c|}
\hline & \multicolumn{2}{|c|}{ Haemodialysis Patients $(n=30)$} \\
\hline & No. of Patients & Percentage \\
\hline \multicolumn{3}{|l|}{ Age (years) } \\
\hline$<55$ & 14 & 38.9 \\
\hline $55-64$ & 5 & 13.9 \\
\hline $65-74$ & 8 & 22.2 \\
\hline $75-85$ & 7 & 19.4 \\
\hline$>85$ & 2 & 5.6 \\
\hline Mean \pm SD & & $61.4 \pm 16.6$ \\
\hline \multicolumn{3}{|l|}{ Renal Diagnosis } \\
\hline Diabetes Mellitus & 11 & 36.6 \\
\hline $\begin{array}{l}\text { Adult polycystic } \\
\text { kidney disease }\end{array}$ & 2 & 6.6 \\
\hline Congenital disorder & 3 & 10 \\
\hline Amyloidosis & 2 & 6.6 \\
\hline Unknown cause & 2 & 6.6 \\
\hline Obstructive uropathy & 1 & 3.3 \\
\hline Glomerulonephritis & 5 & 16.6 \\
\hline Vasculitis & 1 & 3.3 \\
\hline $\begin{array}{l}\text { Hypertensive/ } \\
\text { renovascular disease }\end{array}$ & 3 & 10 \\
\hline \multicolumn{3}{|l|}{ Dialysis duration (months) } \\
\hline $0-12$ & 7 & 6.6 \\
\hline $13-24$ & 12 & 13.3 \\
\hline$>24$ & 11 & 80 \\
\hline Mean duration $\pm \mathrm{SD}$ & - & $25.2 \pm 20.6$ \\
\hline \multicolumn{3}{|l|}{ Comorbid Conditions } \\
\hline $\begin{array}{l}\text { Peripheral vascular } \\
\text { disease }\end{array}$ & 11 & 36.6 \\
\hline Diabetes & 11 & 36.6 \\
\hline Hypertension & 26 & 86.6 \\
\hline Stroke & 6 & 20 \\
\hline Myocardial infarction & 6 & 20 \\
\hline
\end{tabular}

$\mathrm{b}$ Initial renal diagnosis and the length of time on haemodialysis (months) at the point of testing. 


\subsubsection{Effects of dialysis}

\subsubsection{Performance at encoding}

For the conceptual encoding task, data were available for 27 of the 36 ESRD patients. As may be seen from the first 2 rows of Table 4 , both the number of correct vowel counts, and the time taken to make them, were almost identical in the pre-and post-dialysis sessions. Data from 28 patients were available for the perceptual encoding task. Again (Row 3 of Table 4) the difference in time to read the words aloud between the two sessions was very small. None of the differences between sessions was significant on paired t-tests (see Columns 5 and 6 of Table 4).

Table 4. Performance at encoding in patients before and after dialysis in Experiment 1.

\begin{tabular}{llllll}
\hline Task & $\begin{array}{l}\text { Pre-dialysis } \\
\text { mean (SE) }\end{array}$ & $\begin{array}{l}\text { Post-dialysis } \\
\text { mean (SE) }\end{array}$ & n & t & $\boldsymbol{p}$ \\
\hline $\begin{array}{l}\text { Correct vowel counts } \\
\text { Correct count response }\end{array}$ & $29.19(1.42)$ & $29.70(1.44)$ & 27 & 0.55 & 0.59 \\
time (ms) & $3126.56(387.67)$ & $3308.46(367.09)$ & 27 & 0.54 & 0.59 \\
Reading time (ms) & $1140.18(91.39)$ & $1159.82(88.43)$ & 28 & 0.31 & 0.76 \\
\hline
\end{tabular}

\subsubsection{Memory performance}

Differences between pre- and post-dialysis performance of patients in the four different memory assessments (cued recall, category cued recall, word stem completion and category exemplar) were examined with paired sample t-tests. Scores were based on corrected recall data (the number of words recalled in the retrieval phase as proportions). There was no significant difference between the pre- $(M=.079 \mathrm{SD}=.098)$ and post-dialysis $(M=.079 S D$ $=.068)$ test of category cued recall task $(t(13)=0, p=1.0)$, or the cued recall task predialysis $(M=.286 S D=.16)$ and post-dialysis $(M=.282 S D=.181) ; t(13)=0.071, p=.94$. In addition, no significant differences were found between pre-dialysis $(M=.016 \mathrm{SD}=.084)$ and post-dialysis $(M=.003 S D=.082)$ scores on the category exemplar task $(t(15)=0.509, p$ $=.62)$ or on the word stem completion task pre-dialysis $(M=.227 \mathrm{SD}=.12)$ and post-dialysis $(M=.203 S D=.138) ; t(15)=0.527, p=.6$. Overall, dialysis had no significant effects on any of these tests (see Figure 1). 


\subsubsection{End questionnaire}

None of the responses from participants in the implicit groups suggested that they were consciously aware of the relationships between the stimuli at encoding and the cues at retrieval.

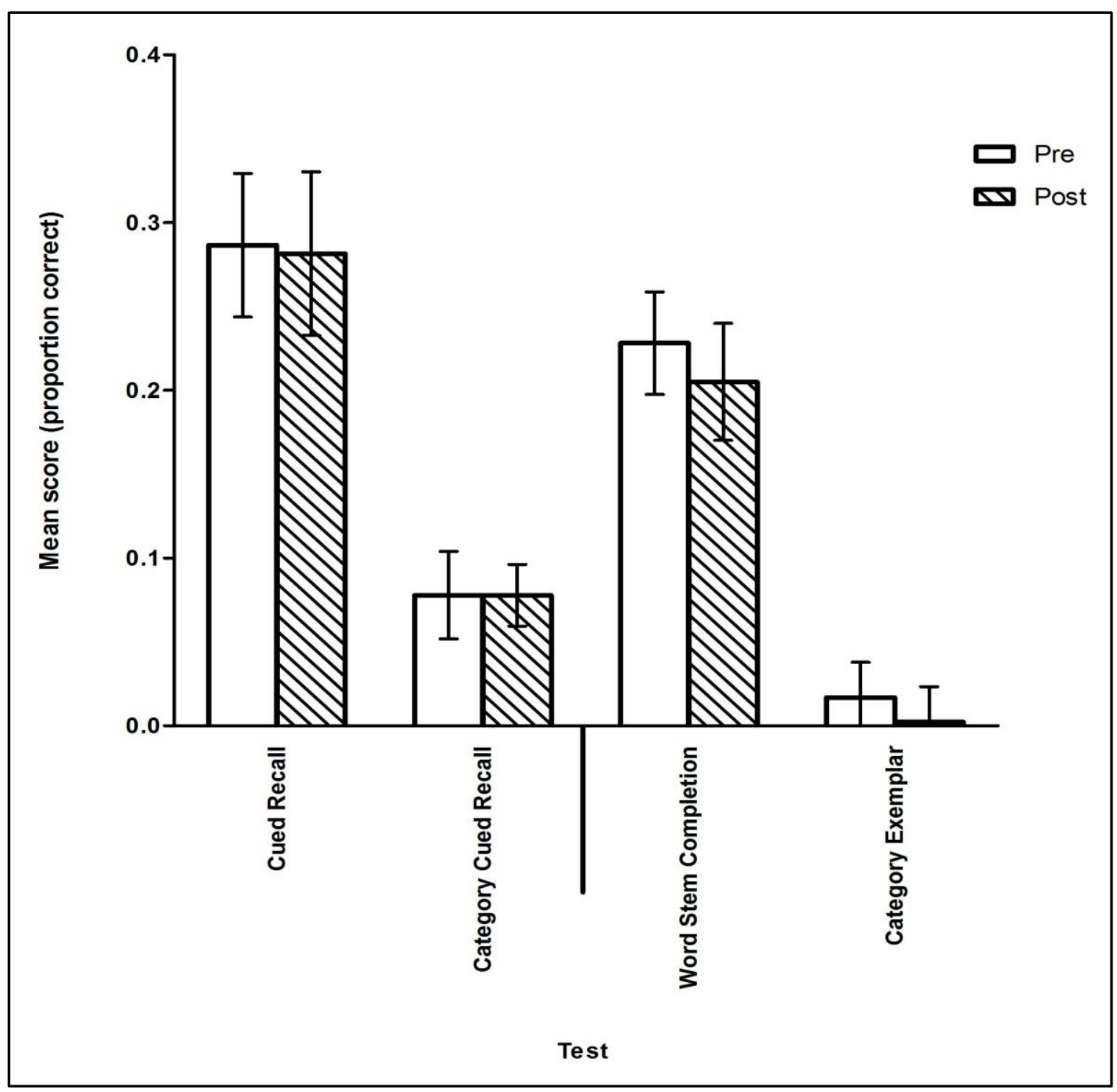

Figure 1. Comparison of pre and post-dialysis assessments in the patient group; scores are proportions of the maximum $(1=$ score of $100 \%)$. No significant differences were found in any of the tasks across the dialysis cycle. Error bars $=1$ S.E. 


\subsubsection{Patients vs. Controls}

\subsubsection{Performance at encoding}

Table 5 shows data from the 29 patients (pre-dialysis) and 23 controls for whom they were available. On the conceptual encoding task (vowel counting), controls were both faster and more accurate. Controls also took less time to read the words aloud in the perceptual encoding task.

Table 5. Performance at encoding in patients and controls before dialysis and controls in Experiment 1.

\begin{tabular}{lllllll}
\hline Task & $\begin{array}{l}\text { Patients pre- } \\
\text { dialysis } \\
\text { mean (SE) }\end{array}$ & $\begin{array}{l}\text { Controls mean } \\
\text { (SE) }\end{array}$ & $\begin{array}{l}\text { Patient } \\
\mathbf{n}\end{array}$ & $\begin{array}{l}\text { Control } \\
\mathbf{n}\end{array}$ & $\mathbf{t}$ & $\boldsymbol{p}$ \\
\hline $\begin{array}{l}\text { Correct vowel } \\
\text { counts }\end{array}$ & $29.41(1.34)$ & $35.00(0.52)$ & 29 & 23 & 3.54 & $<0.001$ \\
$\begin{array}{l}\text { Correct count } \\
\text { response time }\end{array}$ & 3046.41 & $1549.23(90.86)$ & 29 & 23 & 3.58 & $<0.001$ \\
$($ ms $)$ & $(364.87)$ & & & & & \\
Reading time & 1138.47 & $856.52(58.54)$ & 29 & 23 & 2.52 & $<0.015$ \\
$(\mathrm{~ms})$ & $(88.20)$ & & & & & \\
\hline
\end{tabular}

\subsubsection{Performance at retrieval}

Data were separated into conceptual (category cued recall and category exemplar) and perceptual (cued recall and word stem completion) scores, and examined for interactions, as well as for main effects.

A 2 (groups) $\mathrm{x} 2$ (tests) between subjects ANOVA on the conceptual data revealed a significant main effect of group (patients vs. controls) $F(1,62)=4.103, p=.047$. There was no significant main effect of test (explicit vs. implicit) $F(1,62)=0.65, p=.42$, and no significant interaction between group and test $F(1,62)=0.442, p=.51$ (see Figure 2). This finding suggests that controls performed better on the conceptual tasks irrespective of retrieval orientation. For the tests involving perceptual processing, a significant main effect of 
task was found $(F(1,62)=5.3, p=.03)$, indicating that performance was better for all participants on the explicit task as would be expected. In contrast to the conceptual data, no main effect of group was found for perceptual processing $(F(1,62)=0.41, p=.52)$, and no significant interaction between group and task $F(1,62)=0.58, p=.45$ (see Figure 3 ). 


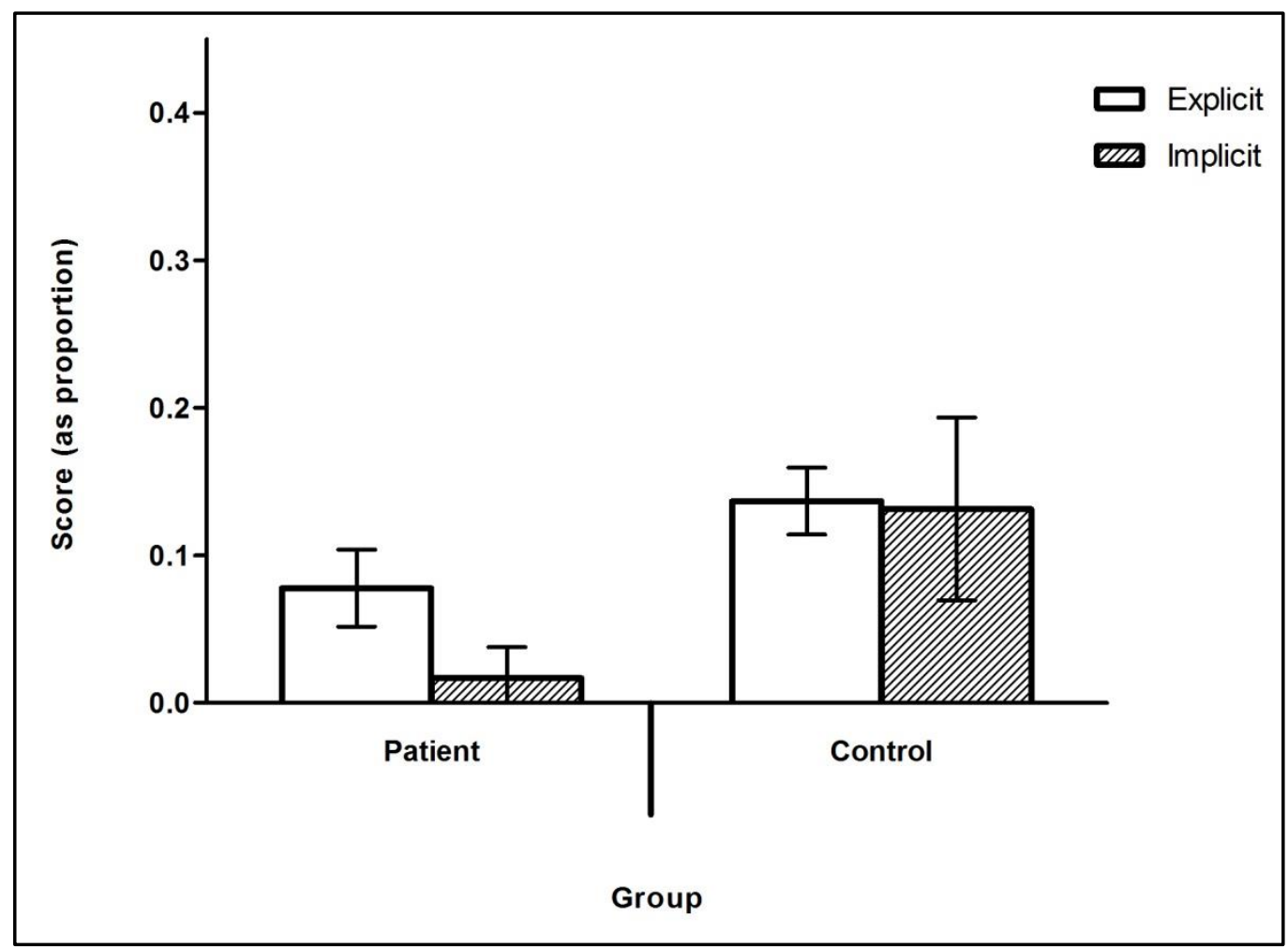

Figure 2. Results of conceptual tasks: data are mean proportions of maximum possible score. Error bars $= \pm 1$ S.E.

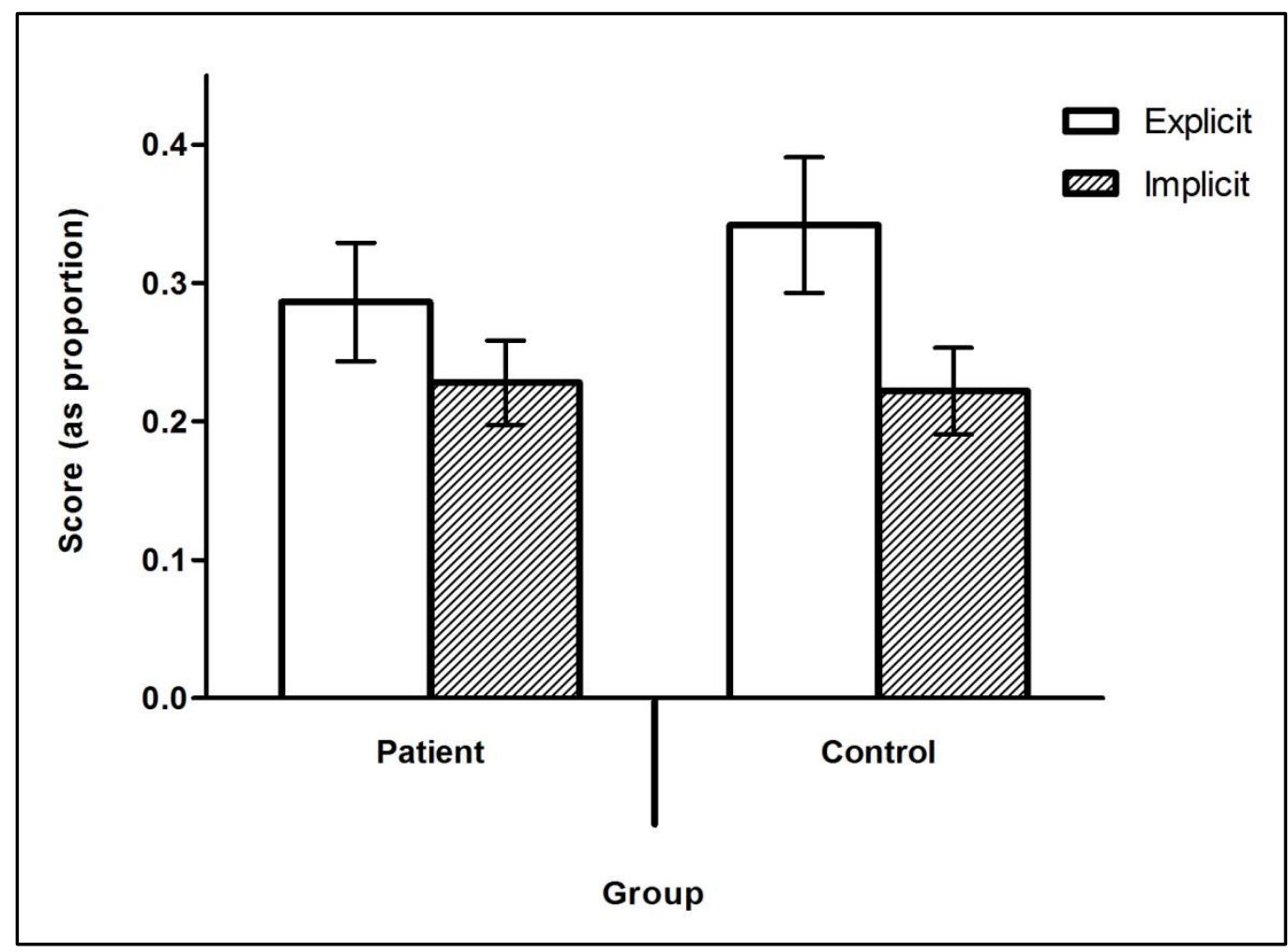

Figure 3. Results of perceptual tasks: data are mean proportions of maximum possible score. Error bars $= \pm 1$ S.E. 


\subsubsection{Correlations}

The main effect of group on the conceptual processing task suggests that ESRD patients are significantly worse at processing semantic information than healthy controls. The effects of ESRD might also be reflected in performance on the neuropsychological tests. To investigate this possibility, Spearman correlations were calculated between scores on the conceptual tests and those on the MMSE, NART, GDS and IADL (and also age, since this might be affecting memory independently of ESRD), and similarly for scores on the perceptual tests. Correlations were calculated separately for controls and patients in the implicit and explicit groups. Age was negatively correlated with performance on the conceptual scores in the explicit control group $(\rho=-0.52, p=0.04)$, but none of the other correlations involving age or IADL was significant. Table 6 shows the other correlation coefficients between the scores on the memory tests, and scores on the MMSE, NART and GDS (with one-tailed $p$ values in brackets). Only one of the correlations between conceptual memory scores and the other variables was significant (MMSE, explicit control group) and that was negative. For perceptual memory (on which the patients were not significantly different from controls), the correlation with NART scores in the explicit patient group was significant. With this latter exception, there was no consistent relationship between memory scores in ESRD and the results of the other neuropsychological scores which might have been affected by the illness.

\subsubsection{Priming effects}

Paired sample t-tests were carried out to confirm that both implicit tasks were successfully priming participants to recall more studied than non-studied words during retrieval. The healthy controls, for the conceptual task, produced significantly more studied $(M=1.85, S D$ $=0.65)$ than non-studied words $(M=1.37, S D=0.47), t(19)=3.02, p<.01, r=0.57$. Similarly for the perceptual task, the controls produced significantly more studied $(M=6.25$, $S D=0.65)$ than non-studied words $(M=2.7, S D=1.49), t(19)=7.1, p<.001, r=0.85$. This confirms that priming was having a significant effect on retrieval rate for both tasks. 
Table 6. Spearman Correlations in Experiment $1^{\mathrm{c}}$

\begin{tabular}{|c|c|c|c|c|c|c|}
\hline & \multicolumn{6}{|c|}{ Patient Group } \\
\hline & \multicolumn{3}{|c|}{ Explicit $(n=14)$} & \multicolumn{3}{|c|}{ Implicit $(n=16)$} \\
\hline & MMSE & NART & GDS & MMSE & NART & GDS \\
\hline Conceptual & $.27(0.18)$ & $.13(0.33)$ & $.08(0.4)$ & $-.02(0.46)$ & $.25(0.17)$ & $-.03(0.45)$ \\
\hline \multirow[t]{4}{*}{ Perceptual } & $.2(0.25)$ & $.51(0.032)^{*}$ & $-.4(0.08)$ & $.21(0.22)$ & $-.29(0.13)$ & $.36(0.8)$ \\
\hline & \multicolumn{6}{|c|}{ Control group } \\
\hline & \multicolumn{3}{|c|}{ Explicit $(n=16)$} & \multicolumn{3}{|c|}{ Implicit $(\mathrm{n}=20)$} \\
\hline & MMSE & NART & GDS & MMSE & NART & GDS \\
\hline Conceptual & $.25(0.18)$ & $.21(0.22)$ & $.32(0.11)$ & $-.45(0.025)^{*}$ & $.07(0.39)$ & $-.05(0.41)$ \\
\hline Perceptual & $.09(0.34)$ & $.16(0.27)$ & $-.07(0.4)$ & $.05(0.41)$ & $.06(0.39)$ & $-.13(0.29)$ \\
\hline
\end{tabular}

cognition and mood in 2 groups of ESRD patients and 2 control groups.

Patients produced significantly more studied $(M=5.9, S D=2.0)$ than non-studied words $(M$ $=2.25, S D=1.13), t(15)=7.54, p<.001, r=0.89$ on the perceptual task. However, on the conceptual task, the difference between studied $(M=1.5, S D=0.6)$ and non-studied words $(M=1.4, S D=0.46)$ was not significant $(t(15)=0.78, p=.45 . r=0.2)$. This confirms that patients were successfully being primed during the perceptual task, whereas their performance was almost at floor in the conceptual task.

\subsection{Discussion}

Patients spent significantly longer studying words at encoding than did controls (see Table 5). Despite this, their performance at retrieval was similar (perceptual) or worse (conceptual). The finding that conceptual priming was absent in the ESRD group is important, as previous studies have reported intact performance in healthy aging (e.g., Isingrini et al. 1995). This apparent implicit retrieval deficit in conceptual memory reflects a previously unreported impairment in comparison with healthy individuals without ESRD.

One might argue that the impairment in conceptual memory found in patients resulted from poorer literacy or comprehension in that group. However, nothing in our measures of the general cognitive ability in this group supports this view. Their average MMSE score was 
almost identical to that of the controls, suggesting normal comprehension. Their average IQ (114.8) was lower than that of the controls (121.8), but well above that of the average of the general population. To achieve this score on the NART requires the correct pronunciation of a range of uncommon words, which is unlikely in a group with poor literacy.

As the stimuli were always presented visually in Experiment 1, it is possible to argue that the impairment in conceptual processing in the patients is in fact a defect in visual processing. This seems unlikely, since perceptual processing was unimpaired in patients. However, to test the idea, and to check the robustness of the conceptual memory dissociation found in Experiment 1, the explicit conceptual memory condition was conducted with auditory presentation.

\section{Experiment 2: Explicit conceptual memory processing in ESRD with auditory presentation}

\subsection{Method}

\subsubsection{Design}

All participants completed an auditory version of the explicit conceptual memory test only. ESRD patients were tested just before one of their weekly dialysis treatment sessions. Controls were tested at a similar time of day (morning or afternoon) to the patient with whom they were matched.

\subsubsection{Participants}

Eighteen patients, ranging from 52 to 86 years of age (Mean: 70.9, S.D: 11.6) were recruited from the renal unit at the Royal Berkshire Hospital in Reading, Berkshire. As in Experiment 1, ESRD patients received haemodialysis three times per week for 3 to 5 hours per treatment, and had been receiving haemodialysis treatment for a minimum of 90 days prior to testing, with a Kt/v $>1.4$. See Table 7 for a summary of patient characteristics. Other details of recruitment and testing of patients were as in Experiment1. Eighteen healthy control participants, matched to the patients on age, sex and education level, (mean age: 70.6 years, S.D: 10.9) were recruited from a research volunteer panel maintained by the Department of Psychology. Other details of recruitment and testing of controls were as in Experiment 1. 
Table 7. Characteristics of patients taking part in Experiment 2.

Haemodialysis Patients $(n=18)$

\section{Characteristic}

Age (years)

$<55$

$55-64$

$65-74$

$75-85$

$>85$

Mean \pm SD

Dialysis Duration (months)

$0-12$

$13-24$

$>24$

Mean \pm SD

Cause of ESRD

Type 2 diabetes mellitus

Type 1 diabetes mellitus

Adult polycystic kidney disease

Chronic kidney disease (unknown cause) 3

Obstructive uropathy

Glomerulonephritis

Vasculitis

Hypertensive/renovascular disease

Surgical loss
No. of Patients

Percentage

11.1

22.2

22.2

33.3

11.1

$70.9 \pm 11.6$

5.6

33.3

61.1

$57.0 \pm 68.3$

11

5.6

5.6

22.2

16.7

5.6

16.7

11.1

11.1

5.6

Comorbid Conditions

Peripheral vascular disease

4

22.2

Diabetes

5

27.8

Hypertension

4

22.2

Stroke

3

16.7

Myocardial infarction

5.6 


\subsubsection{Stimuli and Procedure}

Stimuli were presented via a Toshiba 17.3" LCD screen laptop computer with external speakers, using custom software written in E-Prime 2.0, which allowed timings and amplitudes to be precisely controlled.

\subsubsection{Encoding phase}

Participants listened to a series of 36 words. The words were recorded in a sound-proof booth by a native female English speaker. Each word was stored as a separate sound file, which enabled volume to be equalised between words. Each word was presented in isolation with a four second gap between words. Participants were instructed to count and report verbally the number of syllables in each word. Two of the word lists from Experiment 1 were also used in Experiment 2.

\subsubsection{Retrieval phase}

Retrieval was measured in the same way as in Experiment 1. Participants viewed a series of category labels presented individually (each being shown for approximately 15 seconds) on the computer screen: e.g. carpenter's tools, etc. They were presented with six different categories and instructed to think back to the word list of which they counted syllables. They were asked to say aloud any words remembered from the syllable counting task that fitted the currently presented category, e.g. hammer, etc. All utterances were recorded by the experimenter.

As before, all participants completed a number of standard tests of cognition, ability to function in everyday life, and mood, namely the MMSE, IADL, NART and the Bond-Lader Mood Assessment Scale (Bond \& Lader, 1974). The Bond-Lader rather than the GDS (as in Experiment1) was used as it offers a more sensitive analysis of mood, such as alertness and contentedness. The pattern of responses is different in individuals with high and low levels of depression (Peet et al, 1981). As in Experiment 1, a distractor task, namely completion of the Bond-Lader test, took place between encoding and retrieval. The entire experiment lasted approximately 15 minutes. 


\subsection{Results}

\subsubsection{Demographics}

Demographic data for the participants in Experiment 2 are shown in Table 8. Independent ttests showed no significant differences between patients and healthy controls for age $(t(34)=$ $0.103, p=.918)$ or education level $(t(34)=-0.518, p=.608)$. Significant differences were found between the patient and control groups for NART overall IQ scores $(t(27.7)=-2.736, p$ $=.011), \operatorname{MMSE}(t(34)=-2.928, p=.006)$, and IADL scores $(t(18)=-4.721, p<.001)$. However, even though the groups differed, all scores were within the expected normal range. The scores on the 16 analogue scales of the Bond-Lader test were combined into three main factors (alertness, calmness and contentedness) and the appropriate factor loadings applied to each scale (previously calculated by Bond and Lader, 1974). The scores on these factors did not differ significantly between the patient and control groups (for Alertness, $t(34)=0.43, p$ $=0.67$; for Calmness, $t(34)=0.05, p=0.96$; for Contentedness, $t(34)=1.42, p=0.16$ ).

Table 8. Demographic information for the patient and control groups in Experiment $2^{\mathrm{d}}$.

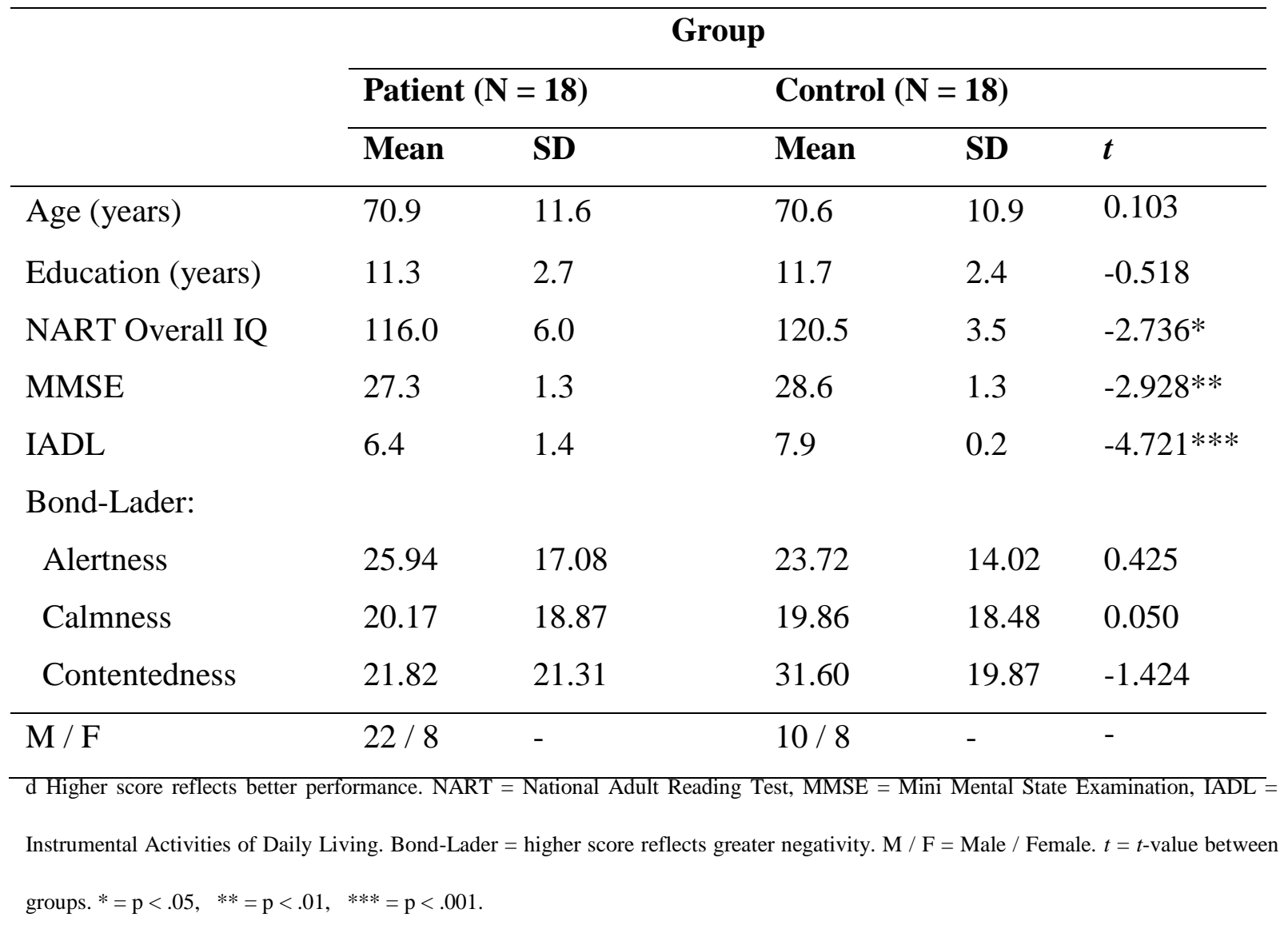


Because we wished to combine results from Experiments 1 and 2, we compared demographic information from the two patient groups. Independent t-tests revealed no significant differences between the two patient samples for Age, $(t(46)=-1.959, p=.056)$, NART Overall IQ, $(t(46)=-0.543, p=.590)$, or MMSE, $(t(46)=-0.057, p=.955)$. Although IADL scores differed significantly between the patient groups $(t(46)=5.099, p<.001)$, both sets of scores were within the normal range, and the difference may reflect the different effects of the timing of treatment on daily life. In summary, we can conclude that general cognitive abilities of the two patient samples are similar enough for comparisons to be made between their memory scores.

2.2.2 Comparison of explicit conceptual memory with presentation in two different modalities

To determine whether stimulus modality had an effect on performance, data from the explicit conceptual visual task in Experiment 1 were compared with the data from the explicit conceptual auditory task in Experiment 2. The data are shown in Figure 4, which reveals that patients perform worse than controls following both modes of presentation, as confirmed by a 2 (patient vs. control) x 2 (visual vs. auditory) between subjects ANOVA. This showed a significant main effect of group, (patients performed worse than controls $-F(1,62)=4.089$, $p$ $=.047$ ), and also a significant main effect of modality (auditory superior to visual $-F(1,62)=$ 18.816, $p<.001)$, but no significant interaction $(F(1,62)=0.072, p=.789)$, suggesting that patients' memory impairment is similar, regardless of modality. 


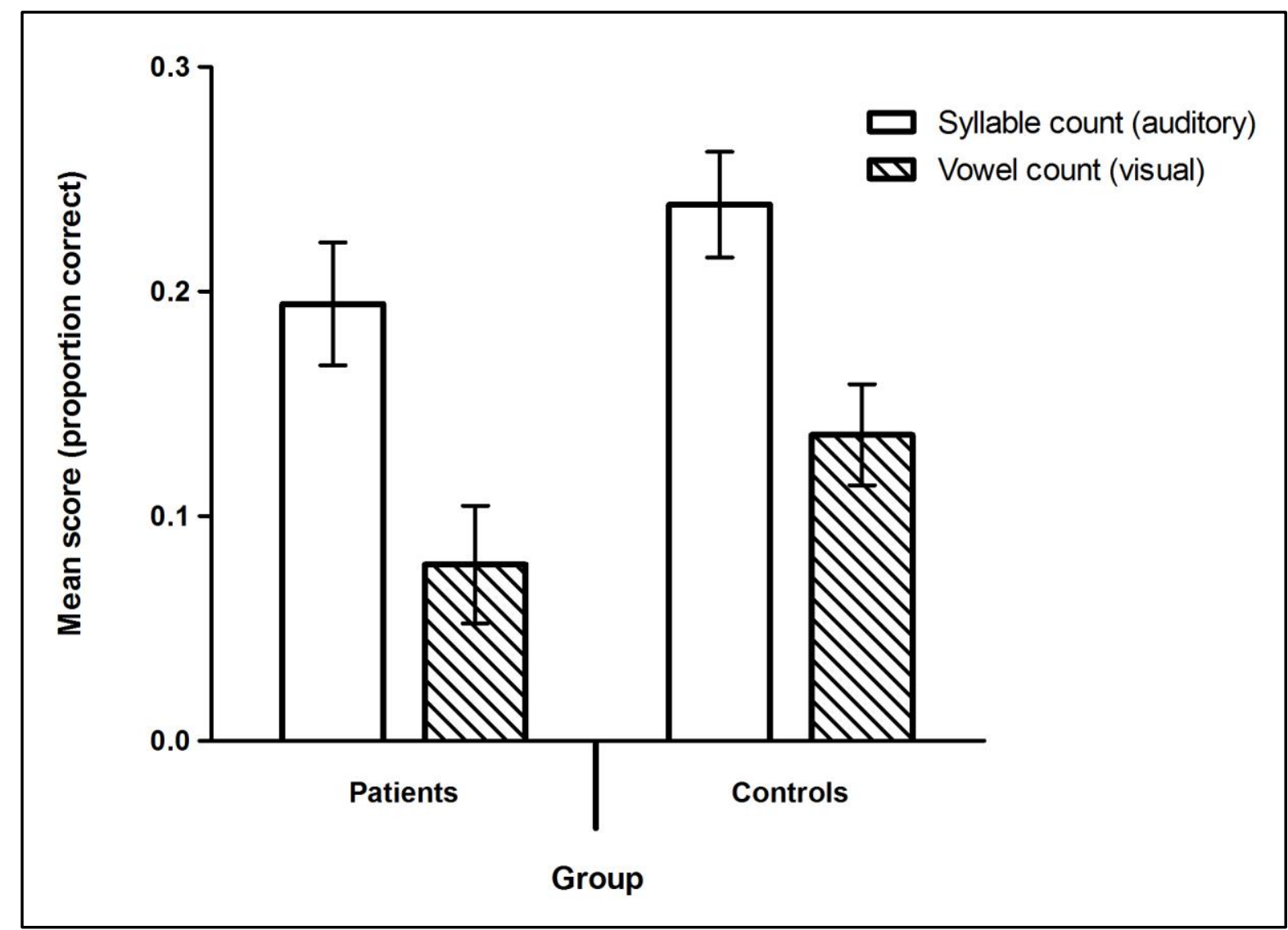

Figure 4. Explicit conceptual recall scores in patients and controls after encoding in two modalities (visual and auditory). Data are mean proportions of maximum possible score (error bars $=1$ S.E.).

\subsection{Discussion}

The finding that the memory impairment in ESRD is similar with auditory presentation to that with visual presentation suggests that the patients' difficulties lie in the memory system, rather than in a particular sensory modality. The finding that performance in both groups was better with auditory presentation was expected, as previous studies have found better recall when stimuli are presented aurally rather than visually during encoding (Levy, 1971; Penney, 1980; Penney, 1989). In addition to a simple auditory stimulus advantage, the modality effect suggests that learning and memory performance is improved when pictures are presented with auditory rather than visual textual aids (Moreno \& Mayer, 1999). A meta-analysis conducted by Ginns (2005) suggests that individuals who learn information with the addition of spoken text performed better than individuals who learned with the aid of printed text. Craik and Lockhart (1972) suggest that the memory trace and variables affecting retention are qualitatively different for aurally and visually presented stimuli. Penney (1975) suggests that 
the auditory store is larger than the visual store, that aurally presented stimuli are processed automatically to at least the level of short-term memory, whereas visual stimuli are not, and that presentation methods when comparing the two modes are optimal for auditory stimuli, as they may provide a richer context. However, these generalisations may only apply to simple stimuli, as used here. Murnane, Phelps \& Malmberg (1999) suggest that real-world recognition and recall is aided by additional information such as associated context and ensemble information - it is very rare that items are presented in isolation.

\subsection{General discussion}

The current study compared implicit with explicit memory and conceptual with perceptual memory in ESRD. In Experiment 1, patients were assessed once before and once immediately after haemodialysis, and also compared to a healthy control group. In the patient group, no effects of dialysis were found. However, in comparison to the control group, patients performed worse on the conceptual task overall, whilst perceptual processing was relatively spared. This finding suggests that memory impairment in ESRD is related to the type of processing (conceptual vs. perceptual), rather than to the type of retrieval (explicit vs. implicit). Moreover, the absence of conceptual priming in the ESRD group represents a previously unreported aspect in which the disease differs from healthy aging.

In order to exclude participants outside the normal range, and because various aspects of cognition have been reported to be impaired in ESRD, correlations between scores on the memory tests and standard tests of cognition and mood were calculated. Because their GDS scores suggested a tendency to depression, the data of 6 patients were excluded from the analysis of Experiment 1, but the remaining patient GDS scores (and their MMSE and NART scores) were within the normal range. It has been suggested that IQ is strongly related to conceptual memory, because of the semantic nature of the task (Spiegel \& Bryant, 1978). However, none of the correlations between patients' performance on the conceptual memory tasks and the NART or MMSE or GDS scores approached significance; only one significant positive correlation (that between perceptual memory and NART score in patients) was found in either group. This aspect of the data needs to be treated with caution, because of sample size, but it suggests that conceptual processing in the patient group may be more affected by ESRD than other general aspects of cognition. 
In Experiment 2, a similar impairment of explicit conceptual memory in patients was found, this time with auditory presentation during encoding. This independence of the effect from presentation modality suggests that it is indeed a memory effect. The superior performance with auditory presentation confirms what has been found for simple stimuli in earlier studies by others. The finding of poorer performance with visual presentation in controls, as well as in patients, suggests that the effect is not due to a selective effect on comprehension in reading in the ESRD group.

In Experiment 1, the patient group performed almost at floor in the conceptual task, whereas in the perceptual task, performance was at a similar level to controls. A possible explanation for the relative sparing of perceptual processing in patients is the presence of environmental context cues during retrieval, easing the demands of recall. Perez, Peynircioglu and Blaxton (1998) studied the effect of children's age on implicit and explicit memory using a category cued recall (conceptual) and a pictorial cued recall task (perceptual). Conceptual performance improved with age, whereas perceptual performance remained consistently high. Perez et al. suggested that this was due to lower memory demands in the perceptual task, with the pictures providing enough additional information to aid with perceptual organisation. Blaxton et al. (1996) found using positron emission topography (PET) that conceptual tasks activated the medial and lateral left hemisphere in frontal and temporal areas, whilst perceptual tasks activated right frontal and temporal as well as posterior areas. Our results are consistent with the view that posterior areas are less affected than temporal areas in ESRD, a hypothesis which could be tested with further brain imaging studies. The vulnerability of temporal regions to the effects of ESRD is also suggested by a study showing that latent learning in patients is different to that in controls (Jones et al, 2015).

We investigated the impact of dialysis on cognition in Experiment 1, by comparing patients' performance before and after dialysis. No significant differences were found between the preand post-dialysis scores, suggesting that dialysis was not having an immediate effect, whether beneficial or detrimental, on patients' memory performance. The evidence on the effect of dialysis on cognition is presently unclear. Murray et al., (2007) found patients to be performing best before dialysis and $24 \mathrm{hr}$ after dialysis; patients' worst performance was during dialysis treatment. This pattern of results suggests that dialysis is having an undesirable effect on cognition, rather than the beneficial effects that have been reported 
elsewhere (Griva et al., 2003; Griva et al., 2006; Kramer, Madl \& Stockenhuber, 1996), or no effect, as found here. Further detailed investigation is needed to gain a better understanding of the fluctuations of cognition in a typical dialysis cycle. One possibly important variable which we did not consider is the time from the previous dialysis at which pre-dialysis testing occurs. For a patient tested on a Monday, this will be about 72 hours, whereas for one tested on a Wednesday this will be about 48 hours. Some of our patients were tested after the longer delay. The similarity in the mean pre- and post-dialysis scores (and standard errors - see Table 4) suggests that these differences were having little effect in our study, but they may be worth considering in future work.

Exactly how ESRD exerts its effects on cognition is not completely clear, though these presumably occur through changes to the blood supply to the brain. As well as the accumulation of waste products, ESRD is associated with a variety of causes and effects, as well as a number of comorbidities (see Tables 3 and 7), many of which are related to the vascular system (diabetes mellitus, vasculitis, glomerulonephritis, and hypertension). Hypertension and diabetes have both been found to cause significant impairments in attention (van den Berg, Kloppenborg, Kessels, Kappelle \& Biessels, 2009), memory (Brady, Spiro \& Gaziano, 2005) and psychomotor speed (Brands, Biessels, de Haan, Kappelle \& Kessels, 2005). In the present patient sample, at least $2 / 3$ rds have been diagnosed with these other conditions. Thus, the cognitive impairments may result from a change in quality and/or quantity in the cerebral blood supply, comorbidities, or a combination of both. The complexity of a typical ESRD patient's diagnosis when trying to make claims about the mechanisms underlying a cognitive impairment suggests the need for caution.

In summary, this study is the first to examine implicit and explicit memory in ESRD and to show a difference between conceptual and perceptual processing. The data suggest that patients are worse than controls when remembering requires processing of the semantic content rather than of the physical features of the stimuli. The type of processing required by the task (conceptual vs. perceptual) is more important than the type of retrieval (explicit vs. implicit) in memory failures in ESRD. It may be important for clinicians to note such impairments when discussing with patients complex dietary advice or medication regimes as part of their treatment. Additional steps may need to be taken to ensure that possibly 
complicated information is correctly retained and recalled by patients, and so adherence to treatment is improved.

Our tentative conclusion for this study of memory in ESRD is that frontal and temporal areas are more impaired than posterior areas in the illness. Further brain imaging and behavioural studies are needed to confirm this hypothesis, and to determine which features of perceptual processing underlie the normal aspects of memory performance, and how these interact with the effects of dialysis. 


\subsection{Acknowledgments}

D J W Jones was supported by an ESRC CASE Research Studentship, and R Hadid by an Undergraduate Summer Bursary from the Experimental Psychology Society, during the course of this research. We thank the staff of the Renal Unit, Royal Berkshire Hospital, Reading, UK, for their co-operation, and all our participants for their time and commitment. 


\subsection{References}

Aggleton, J. P., \& Brown, M. W. (1999). Episodic memory, amnesia, and the hippocampal anterior thalamic axis. Behavioral and Brain Sciences, 22, 425-489. doi: $10.1017 / \mathrm{s} 0140525 \times 99002034$

Becaria, A., Campbell, A., \& Bondy, S. C. (2002). Aluminum as a toxicant. Toxicology and Industrial Health, 18, 309-320. doi: 10.1191/0748233702th157oa

Blaxton, T. A., Bookheimer, S. Y., Zeffiro, T. A., Figlozzi, C. M., Gaillard, W. D., \& Theodore, W. H. (1996). Functional Mapping of Human Memory Using PET:

Comparisons of Conceptual and Perceptual Tasks. Canadian Journal of Experimental Psychology, 50, 42-56. doi: 10.1037/1196-1961.50.1.42

Bond, A. \& Lader, M. (1974). The use of analogue scales in rating subjective feelings. British Journal of Medical Psychology 47, 211-218. doi: 10.1111/j.2044-8341.1974.tb02285.x

Brady, C. B., Spiro III, A., \& Gaziano, J. M. (2005). Effects of age and hypertension status on cognition: the Veterans Affairs Normative Aging Study. Neuropsychology, 19(6), 770. doi: 10.1037/0894-4105.19.6.770

Brands, A., Biessels, G. J., de Haan, E. H., Kappelle, L. J., \& Kessels, R. P. (2005). The effects of Type 1 Diabetes on Cognitive Performance: A meta-analysis. Diabetes Care, 2005. doi: 10.2337/diacare.28.3.726

Buchman, A. S., Tanne, D., Boyle, P. A., Shah, R. C., Leurgans, S. E., Bennett, D. A. (2009). Kidney function is associated with the rate of cognitive decline in the elderly. Neurology, 73, 920-927. doi: 10.1212/WNL.0b013e3181b72629

Butler, L. T., \& Berry, D. C. (2001). Implicit memory: intention and awareness revisited. Trends in Cognitive Sciences, 5, 192-197. doi: 10.1016/s1364-6613(00)01636-3 
Benjamin Clarke, A. J., \& Butler, L. T. (2008). Dissociating word stem completion and cued recall as a function of divided attention at retrieval. Memory, 16(7), 763-772. doi: $10.1080 / 09658210802261116$

Coltheart, M (1981). The MRC psycholinguistic database. Quarterly Journal of Experimental Psychology Section A: Human Experimental Psychology, 33:4, 497-505. doi: 10.1080/14640748108400805

Craik, F. I., M. \& Lockhart, R. S. (1972). Levels of processing: A framework for memory research. Journal of verbal learning and verbal behavior, 11(6), 671-684. doi: doi:10.1016/S0022-5371(72)80001-X

Elias, M. F., Elias, P. K., Seliger, S. L., Narsipur, S. S., Dore, G. A., \& Robbins, M. A. (2009). Chronic kidney disease, creatinine and cognitive functioning. Nephrology Dialysis Transplantation, 24, 2446-2452. doi: 10.1093/ndt/gfp107

El-Nahas, A. M., \& Bello, A. K. (2005). Chronic kidney disease: the global challenge. Lancet, 365, 331-340. doi: 10.1016/s0140-6736(05)17789-7

Etgen, T., Sander, D., Chonchol, M., Briesenick, C., Poppert, H., Forstl, H., \& Bickel, H. (2009). Chronic kidney disease is associated with incident cognitive impairment in the elderly: the INVADE study. Nephrology Dialysis Transplantation, 24, 3144-3150. doi: $10.1093 / \mathrm{ndt} / \mathrm{gfp} 230$

Folstein, M. F., Folstein, S. E., \& McHugh, P. R. (1975). "Mini-Mental State": A practical method for grading the cognitive state of patients for the clinician. Journal of Psychiatric Research, 12, 189-198. doi: 10.1016/0022-3956(75)90026-6

Gabrieli, J. D. E., Fleischman, D. A., Keane, M. M., Reminger, S. L., \& Morrell, F. (1995). Double dissociation between memory systems underlying explicit and implicit memory in the human brain. Psychological Science, 6(2), 76-82. doi: 10.1111/j.1467-9280.1995.tb00310.x 
Ginns, P. (2005). Meta-analysis of the modality effect. Learning and Instruction, 15(4), 313331. doi: 10.1016/j.learninstruc.2005.07.001

Griva, K., Newman, S. P., Harrison, M. J., Hankins, M., Davenport, A., Hansraj, S., \& Thompson, D. (2003). Acute neuropsychological changes in hemodialysis and peritoneal dialysis patients. Health Psychology, 22, 570-578. doi: 10.1037/02786133.22 .6 .570

Griva, K., Thompson, D., Jayasena, D., Davenport, A., Harrison, M., \& Newman, S. P. (2006). Cognitive functioning pre- to post-kidney transplantation - a prospective study. Nephrology Dialysis Transplant, 21, 3275-3282. doi: 10.1093/ndt/gfl385

Hart, R. P., \& Kreutzer, J. S. (1988). Renal system. In R. E. Tarter, D. H Van Thiel, \& K. L. Edwards (Eds.), Medical neuropsychology: The impact of disease on behaviour (pp.99-120). New York: Plenum Press.

Isingrini, M., Vazou, F., \& Leroy, P. (1995). Dissociation of implicit and explicit memory tests: Effect of age and divided attention on category exemplar generation and cued recall. Memory \& Cognition, 23(4), 462-467. doi: 10.3758/BF03197247

Jassal, S. V., Devins, G. M., Chan, C. T., Bozanovic, R., \& Rourke, S. (2006). Improvements in cognition in patients converting from thrice weekly hemodialysis to nocturnal hemodialysis: A longitudinal pilot study. Kidney International, 70, 956-962. doi: 10.1038/sj.ki.5001691

Jones, D. J. W., Butler L.T., Harris, J.P.., \& Vaux, E.C. (2015). Latent learning in End Stage Renal Disease (ESRD). Physiology and Behaviour, 142, 42-47. doi: 10.1016/j.physbeh.2015.01.033

Kramer, L., Madl, C., Stockenhuber, F., Yeganehfar, W., Eisenhuber, E., Derfler, K., Lenz, K., Schneider, B., Grimm, G. (1996). Beneficial effects of renal transplantation on cognitive brain function. Kidney International, 49, 833-838. doi: 10.1038/ki.1996.115 
Kurella, M., Chertow, G. M., Luan, J., \& Yaffe, K. (2004). Cognitive Impairment in Chronic Kidney Disease. American Geriatrics Society, 52, 1863-1869. doi: 10.1111/j.15325415.2004.52508.x

Lawton, M.P., and Brody, E.M. (1969). Assessment of older people: Self-maintaining and instrumental activities of daily living. Gerontologist, 9, 179-186. doi: 10.1093/geront/9.3_Part_1.179

Levy, B. A. (1971). Role of articulation in auditory and visual short-term memory. Journal of Verbal Learning and Verbal Behavior, 10(2), 123-132. doi:10.1016/S00225371(71)80003-8

Madero, M., Gul, A., \& Sarnak, M. J. (2007). Review: Cognitive function in chronic kidney disease. Seminars in dialysis, 21, 29-37. doi: 10.1111/j.1525-139X.2007.00384.x

Martin, A. (2007). The representation of object concepts in the brain. Annual Review of Psychology, 58(1), 25-45. doi: 10.1146/annurev.psych.57.102904.190143

Moreno, R., \& Mayer, R. E. (1999). Cognitive principles of multimedia learning: The role of modality and contiguity. Journal of educational psychology, 91(2), 358. doi: 10.1037/0022-0663.91.2.358

Murnane, K., Phelps, M. P., \& Malmberg, K. (1999). Context-dependent recognition memory: The ICE theory. Journal of Experimental Psychology: General, 128(4), 403. doi: 10.1037/0096-3445.128.4.403

Murray, A. M., Pederson, S. L., Tupper, D. E., Hochhalter, A. K., Miller, W. A., Qi Li, M. S., Zaun, D., Collins, A. J., Kane, R., \& Foley, R. N. (2007). Acute variation in cognitive function in hemodialysis patients: A cohort study with repeated measures. American Journal of Kidney Diseases, 50(2), 270-278. doi: 10.1053/j.ajkd.2007.05.010

Nelson, H. E., \& Willeson, J. R. (1991). National Adult Reading Test (2nd ed.). Windsor, UK: NFER-Nelson. 
Peet, M., Ellis, S., \& Yates, R.A. (1981). The effect of level of depression on the use of visual analogue scales by normal volunteers. British Journal of Clinical Pharmacology 12, 171-178. doi: 10.1111/j.1365-2125.1981.tb01197.x

Penney, C. G. (1975). Modality effects in short-term verbal memory. Psychological Bulletin, 82(1), 68. doi: 10.1037/h0076166

Penney, C. G. (1980). Order of report in bisensory verbal short-term memory. Canadian Journal of Psychology, 34, 190-195. doi: 10.1037/h0081038

Penney, C. G. (1989). Modality effects and the structure of short-term verbal memory. Memory \& Cognition, 17(4), 398-422. doi: 10.3758/BF03202613

Pereira, A. A., Weiner, D. E., Scott, T., \& Sarnak, M. J. (2005). Cognitive Function in Dialysis Patients. American Journal of Kidney Diseases, 45 (3), 448-462. doi: 10.1053/j.ajkd.2004.10.024

Perez, L. A., Peynircioglu, Z. F., \& Blaxton, T. A. (1998). Developmental differences in implicit and explicit memory performance. Journal of Experimental Child Psychology, 70, 167-185. doi: 10.1006/jecp.1998.2449

Pobric, G., Jefferies, E., Lambon Ralph, M. A. (2007). Anterior temporal lobes mediate semantic representation: Mimicking semantic dementia by using rTMS in normal participants. Proceedings of the National Academy of Sciences of the United States of America, 104 (50), 20137-20141. doi: 10.1073/pnas.0707383104

Roediger, H. L. (1990). Implicit memory: Retention without remembering. American Psychologist, 45(9), 1043-1056. doi: 10.1037/0003-066X.45.9.1043

Schacter, D. L. (1992). Priming and Multiple Memory Systems: Perceptual Mechanisms of Implicit Memory. Journal of Cognitive Neuroscience, 4 (3), 244-256. doi: 10.1162/jocn.1992.4.3.244 
Spiegel, M. R., \& Bryant, N. D. (1978). Is speed of processing information related to intelligence and achievement? Journal of Educational Psychology, 70, 904-910. doi: 10.1037/0022-0663.70.6.904

Thornton, W. L., Shapiro, R. J., Deria, S., Gelb, S., \& Hill, A. (2007). Differential impact of age on verbal memory and executive functioning in chronic kidney disease. Journal of International Neuropsychological Society, 13, 344-353. doi: $10.1017 / \mathrm{S} 1355617707070361$

US Renal Data System. (2011). USRDS 2011 Annual Data Report: Atlas of Chronic Kidney Disease and End-Stage Renal Disease in the United States. Bethesda, MA: National Institutes of Health, National Institute of Diabetes and Digestive and Kidney Diseases.

van den Berg, E., Kloppenborg, R. P., Kessels, R. P., Kappelle, L. J., \& Biessels, G. J. (2009). Type 2 diabetes mellitus, hypertension, dyslipidemia and obesity: A systematic comparison of their impact on cognition. Biochimica et Biophysica Acta (BBA)-Molecular Basis of Disease, 1792(5), 470-481. doi: 10.1016/j.bbadis.2008.09.004

Visser, M., Jefferies, E., \& Lambon Ralph, M. A. (2010). Semantic Processing in the Anterior Temporal Lobes: A Meta-analysis of the Functional Neuroimaging Literature. Journal of Cognitive Neuroscience, 22 (6), 1083-1094. doi: 10.1162/jocn.2009.21309

Williams, M. A., Sklar, A. H., Burright, R. G., \& Donovick P. J. (2003). Temporal effects of dialysis on cognitive functioning in patients with ESRD. American Journal of Kidney Diseases, 43, 705-711. doi: 10.1053/j.ajkd.2003.12.031

Yesavage, J.A., Brink, T.L., Rose, T.L., Lum, O., Huang, V., Adey, M.B., \& Leirer, V.O. (1983). Development and validation of a geriatric depression screening scale: A preliminary report. Journal of Psychiatric Research, 17, 37-49. doi: 10.1016/00223956(82)90033-4 
Appendix 1. Word lists used in Experiment 1 (see text for details of assignment of lists to participants).

Key: $\mathrm{V}=$ Version; $\mathrm{L}=$ List

\begin{tabular}{|c|c|c|c|}
\hline V1L1 & V1L2 & V2L1 & V2L2 \\
\hline Lock & Pitcher & Fish & Flower \\
\hline Gulf & Bother & Monkey & Loop \\
\hline Malaria & Purple & Vase & Vest \\
\hline Aunt & Nose & Shoe & Maiden \\
\hline Sweater & Triumph & Craft & Tire \\
\hline Triumph & Lock & Retail & Turtle \\
\hline Violin & $\begin{array}{l}\text { Iyphoon } \\
\text { Sock }\end{array}$ & Savage & Genius \\
\hline Star & Dragon & Slipper & Meadow \\
\hline Pitcher & Torment & Silence & Camel \\
\hline Wheel & Swan & Leaf & Fish \\
\hline Diamond & Clock & Lop & Deer \\
\hline Celery & Glass & Genius & Glitter \\
\hline Surgery & Joke & Whistle & Arrow \\
\hline Bell & Coat & Plague & Mouse \\
\hline Port & Aunt & Bureau & Destiny \\
\hline Foot & Flag & Horse & Savage \\
\hline Piano & Wheel & Motive & Craft \\
\hline Rainbow & Port & Tire & Motive \\
\hline Thumb & Rabbit & Basket & Retail \\
\hline Joke & Star & Screw & Drum \\
\hline Twinkle & Cherry & Destiny & Incline \\
\hline Traitor & Dive & Smile & Cocaine \\
\hline Boot & & Perfume & Bureau \\
\hline Bother & $\begin{array}{l}\text { Frog } \\
\text { Glove }\end{array}$ & Speech & Speech \\
\hline Blouse & Balloon & Spider & Slumber \\
\hline Giraffe & Enot & Mystery & Silence \\
\hline Dive & root & Sailor & Feather \\
\hline Deceive & Trumpet & Helmet & Inspire \\
\hline Spoon & Saliva & Digest & Smile \\
\hline Coat & Piano & Harp & Marble \\
\hline Glass & & Flower & Horse \\
\hline Nose & Scarlet & Stool & Mystery \\
\hline
\end{tabular}


Appendix 2. Category labels for the word lists used in Experiment 1

Key: $\mathrm{V}=$ Version; $\mathrm{L}=$ List

V1L1

Precious stones

Units of time

Relatives

Metals

Reading materials

Military titles

V2L1

Articles of furniture

Parts of human body

Fruits

Weapons

Types of human dwelling

Alcoholic beverages
V1L1

Units of distance

Four-footed animals

Kinds of cloth

Colours

Kitchen utensils

Parts of speech

V2L2

Countries

Carpenter's tools

Members of the clergy

Food flavouring

Types of fuel

Professions 